\title{
POLÍTICA DEMOCRÁTICA E PLURALISMO AGONISTA
}

\author{
Chantal Mouffe
}

Universidade de Westminster (Reino Unido) 

As sociedades liberal-demócratas actuais caracterízanse por unha incapacidade cada vez maior de percibiren os problemas políticos aos que se enfrontan; é dicir, aqueles problemas para os que non abonda con tomar meras decisións técnicas, senón tamén propiamente políticas, decisións que se adoptan entre diversas alternativas reais que supoñen a presenza de proxectos opostos, mais lexítimos, sobre como organizar a vida diaria desas sociedades. Tal cousa non resulta sorprendente, visto que a mensaxe que, malia que de xeitos diferentes, transmiten as correntes máis recentes da teoría política e a socioloxía -por non mencionar as prácticas dominantes dos partidos políticos maioritario- é que o modelo político baseado na confrontación quedou obsoleto e entramos nunha nova fase de modernidade reflexiva na cal se pode construír un consenso inclusivo arredor dun "centro radical». Todos aqueles que discrepan deste consenso son tachados de arcaicos ou condenados por «malvados» ou «inimigos da civilización».

Existen moitas razóns que explican a desaparición dunha perspectiva realmente política; algunhas delas teñen que ver co predominio dun réxime globalizador neoliberal, e outras co tipo de cultura de consumo individualista que invade a meirande parte das sociedades industriais avanzadas dos nosos tempos. Desde un punto de vista máis estritamente político, está claro que a caída do comunismo e a desaparición das fronteiras políticas que estruturaran o imaxinario político ao longo de case todo o século XX levaron ao derrubamento dos marcadores políticos da sociedade. O esvaecemento dos límites que separan a dereita e a esquerda, o cal presenciamos decontino e que tantos celebran como un avance, representa sen dúbida un perigo para a política democrática. Xaora, a esfera pública política e democrática viuse gravemente debilitada pola falla dun debate autenticamente "agonista» que verse sobre as alternativas á actual orde hexemónica que se poden presentar. Aquí radica a orixe da crecente desafección polas institucións liberal-demócratas, que se manifesta nunha menor partici- 
pación electoral e na atracción que exercen os partidos populistas de dereitas que poñen en dúbida o sistema político.

\section{OS PUNTOS FRACOS DA TEORÍA LIBERAL-DEMÓCRATA}

Como teórica política interésame especialmente a responsabilidade que ten a teoría política na actual incapacidade de reflexionar en sentido político, así como o papel que este pensamento teórico desempeñou na desaparición dunha perspectiva propiamente política; velaquí a primeira cuestión que vou analizar.

Nestes últimos anos, a tradicional visión da democracia en canto conglomerado de intereses, o modelo "agregador», vai sendo desprazado por un novo paradigma que, co nome de "democracia deliberativa», está a impor con rapidez as condicións do debate; un dos seus principios fundamentais consiste en que os asuntos políticos son de natureza moral e, xa que logo, susceptibles de recibir un tratamento racional. Segundo esta perspectiva, o obxectivo das sociedades democráticas é a creación dun consenso racional que se debe acadar mediante os procedementos deliberativos axeitados, cuxo propósito é o de adoptar decisións que representen un punto de vista imparcial e que beneficien a todos por igual. Todos aqueles que cuestionen a mera idea de alcanzar tal consenso racional e que afirmen que a política é un eido en que, de xeito racional, sempre se debe esperar que existan discordancias son acusados de minar a propia posibilidade de que exista a democracia. Como di, por exemplo, Habermas, «se as cuestións de xustiza non poden ir para alén de como diversas formas de vida que compiten entre si entenden as súas accións en sentido ético, e se os conflitos de valores e as oposicións que son relevantes existencialmente inflúen en toda materia polémica, ao final acabaremos con algo semellante a como Carl Schmitt entende a política» (Habermas 1996, p. 1493).

Nestes tempos, o achegamento teórico que máis de moda está é o de concibir a natureza do político como algo afín á moralidade, entendida en sentido racionalista e universalista. $\mathrm{O}$ discurso da moralidade pasou hoxe a ocupar o lugar da metanarrativa, o lugar que substitúe os desacreditados discursos políticos e sociais á hora de ofrecer as directrices da acción colectiva. E rapidamente se torna no único vocabulario lexítimo, posto que, no canto de diferenciar 
entre a esquerda e a dereita, agora comínasenos a distinguir entre o bo e o malo.

Isto conduciu á eliminación da dimensión de antagonismo que non se pode erradicar da política, así como ao desprazamento do político ante o pulo do xurídico e o moral, que se perciben como terreos especialmente indicados para a toma de decisións imparciais. Esta substitución do político polo xurídico apréciase con claridade na obra de, entre outros, John Rawls, quen presenta o tribunal supremo como o mellor exemplo do que denomina «libre exercicio da razón pública», que ao seu ver constitúe o modelo mesmo da deliberación democrática. Outro exemplo podémolo atopar na obra de Ronald Dworkin, quen en moitos dos seus ensaios lle dá primacía ao poder xudicial independente, en canto intérprete da moralidade política dunha comunidade. Segundo este autor, resulta máis conveniente que todas as cuestións fundamentais ás que se enfronta unha comunidade política nos eidos do emprego, a educación, a censura, a liberdade de asociación, etc., as resolvan os xuíces, sempre e cando interpreten a constitución tomando como referencia o principio da igualdade política. Pouco queda para debater no terreo político.

Nin sequera os pragmatistas como Richard Rorty, malia criticaren notablemente a postura racionalista cubrindo un amplo terreo nos seus ataques, ofrecen unha alternativa axeitada. O problema de Rorty é que, aínda que dun modo diferente, tamén acaba por darlle prioridade ao consenso e pasa por alto a dimensión do político. $\mathrm{O}$ consenso polo que avoga ten que acadarse, abofé, por medio da persuasión e a «educación sentimental», non mediante a argumentación racional, mais non por iso deixa el de crer na posibilidade de lograr un consenso total e, en consecuencia, na eliminación do antagonismo.

De feito, a conxuntura actual pode entenderse como a posta en práctica dunha tendencia que, como argúe Carl Schmitt, se inscribe no propio celme do liberalismo, cuxa incapacidade constitutiva para pensar nun sentido verdadeiramente político explica por que sempre tivo de recorrer a outro tipo de discurso: o económico, o moral ou o xurídico. A forza da crítica de Schmitt radica en que pon en primeiro plano o que constitúe o principal punto fraco do pensamento liberal: a súa incapacidade de aprehender a especificidade do político. En The Concept of the Political, o autor afirma que «dun xeito moi sistemático, o pensamento liberal elude ou pasa por alto o Estado e a política e, en troques, móvese 
entre a típica polaridade recorrente da existencia de dúas esferas heteroxéneas: a ética e a economía, o intelecto e o comercio, a educación e a propiedade. A substancial desconfianza no Estado e na política explícase doadamente por referencia aos principios dun sistema polo cal o individuo non debe deixar de ser terminus a quo nin terminus ad quem» (Schmitt, 1976, p. 70).

No entanto, o pensamento liberal necesariamente ten que estar cego ante o político por mor do seu individualismo, que lle impide comprender a formación das identidades colectivas. Mais o político ocúpase desde o primeiro momento das formas colectivas de identificación, dado que neste campo sempre estamos a falar da formación do «nós», en oposición ao «eles». O político ten que ver co conflito e o antagonismo, e a súa differentia specifica, como o denomina Schmitt, radica na distinción entre amigo e inimigo. Non é de estrañar, daquela, que o racionalismo liberal non poida entender a súa natureza, dado que para o racionalismo é preciso negar mesmamente a imposibilidade de erradicar o antagonismo. O liberalismo ten que negar o antagonismo porque, ao poñer de relevo o inexorable momento de tomar unha decisión -no sentido máis contundente de ter que decidir nun eido sobre o que non se pode decidir-, o que revela o antagonismo son os propios límites de todo consenso racional.

É esta negación do antagonismo o que impide que a teoría liberal perciba de xeito adecuado a política democrática. $\mathrm{O}$ político, na súa dimensión antagonista, non se pode eliminar simplemente con negalo, con desexar que desapareza -que é a típica postura liberal-; unha negación así só conduce á impotencia, a impotencia que caracteriza o pensamento liberal cando se ve cara a cara co xurdimento de antagonismos que, segundo a súa teoría liberal, deberían corresponder a unha época pasada na cal a razón aínda non dera controlado as presuntamente arcaicas paixóns. Velaquí as raíces da incapacidade actual para comprender o carácter e as causas dos novos antagonismos que apareceron logo da fin da guerra fría. Polo tanto, resulta de vital importancia escoitar a Schmitt cando afirma que o político non se pode entender «máis que no contexto da omnipresente posibilidade de agrupar amigos e inimigos, con independencia dos aspectos morais, estéticos e económicos que comporte tal posibilidade» (Schmitt, 1976, p. 35). Schmitt está no certo ao chamar a nosa atención sobre o feito de que o político está ligado á existencia dunha dimensión de hostilidade nas sociedades humanas, hostilidade que pode adoptar numerosas formas e 
manifestarse en moi diversos tipos de relacións sociais. Segundo manteño eu, recoñecer isto debería constituír o punto de partida dunha axeitada reflexión arredor dos obxectivos da política democrática.

Certamente, Schmitt nunca elaborou esas apreciacións de maneira teórica e é preciso formulalas con maior rigor. Eu querería sinalar que isto se pode facer coa axuda da crítica do esencialismo realizada desde varias correntes do pensamento contemporáneo, que amosa que un dos principais problemas do liberalismo radica en que desprega unha lóxica do social baseada na concepción do existir en tanto que estar presente, e en que concibe a obxectividade como algo inherente ás cousas en si mesmas. Por iso o liberalismo non pode aprehender o proceso de construción das identidades políticas; é incapaz de recoñecer que unha identidade só pode existir cando se constrúe en canto «diferenza» e que toda obxectividade social se constitúe mediante actos de poder. O que o liberalismo se nega a admitir é que toda forma de obxectividade social é política en última instancia e debe amosar as pegadas deixadas polos actos de exclusión que rexen a súa constitución.

Chegados a este punto, pode axudar a facer máis explícito este argumento a noción do "exterior constitutivo", termo proposto por Henry Staten para denominar varios temas que desenvolvera Jacques Derrida mediante conceptos como «suplemento», «marca» e «diferenza». O propósito deste termo é o de subliñar que a creación dunha identidade supón o establecemento dunha diferenza, a cal adoita construírse segundo unha xerarquía; por exemplo, entre materia e forma, branco e negro, homes e mulleres, etc. Unha vez que entendemos que toda identidade é relacional e que a afirmación dunha diferenza -é dicir, a percepción de algo «alleo» que constitúe o «exterior» desa identidade- é unha condición previa para unha identidade existir, pódese formular mellor a argumentación de Schmitt sobre a posibilidade, sempre presente, de establecer unha relación entre amigo e inimigo; ou, dito doutro xeito, xa podemos comezar a pensar en como unha relación social se pode tornar no campo de cultivo do antagonismo.

Ao falarmos de identidades políticas, que nunca deixan de ser identidades colectivas, estamos a referirnos á creación dun «nós» que só pode existir unha vez que se delimita un «eles». Isto non significa, por suposto, que esta relación sexa antagónica por necesidade, senón que sempre existe a posibilidade de que 
se torne nunha relación entre amigo e inimigo; o cal acontece cando se empeza a percibir que os demais, que ata o momento foran considerados simplemente diferentes, cuestionan a nosa identidade e ameazan a nosa existencia. A partir dese punto, toda forma de relación entre nós e eles, xa sexa relixiosa, étnica ou económica, convértese no locus dun antagonismo.

Neste respecto, o que importa é recoñecer que a propia condición de que sexa posible que se formen identidades políticas constitúe, así mesmo, a condición de que é imposible que exista unha sociedade da que se eliminase todo antagonismo. Xa que logo, este antagonismo é unha posibilidade que está sempre presente, como subliña Schmitt en repetidas ocasións. Tal dimensión antagonista é o que propoño chamar "o político», distinguíndoo da "política», que se refire ao conxunto de prácticas e institucións cuxo obxectivo é o de crear unha orde, organizar a convivencia humana nunhas condicións que son sempre conflitivas porque están imbuídas do "político». Para usarmos a terminoloxía heideggeriana, poderiamos dicir que "o político» se sitúa ao nivel do ontolóxico, mentres que a política se atopa no ámbito do óntico.

\section{PLURALISMO AGONISTA}

Ao meu ver, para entendermos a natureza da política democrática e o desafío ao que se enfronta, precisamos unha alternativa ás dúas posturas principais da teoría política democrática. Un destes achegamentos, o modelo agregativo, considera que os actores políticos se moven na procura da consecución dos seus intereses, en tanto que o outro, o modelo deliberativo, subliña a función que cumpren a razón e as consideracións morais. $\mathrm{O}$ que ambos os modelos deixan de lado é o papel crucial que desempeñan as "paixóns" na creación das identidades políticas colectivas, pois a política democrática non se entende sen recoñecer que nas paixóns se acha a forza que lle dá vida ao terreo político. É precisamente esta deficiencia o que tenta remediar o modelo agonista da democracia, tratando todas as cuestións que non abordaran axeitadamente os outros dous modelos por estaren contidos nun marco individualista e racionalista.

En poucas palabras, o argumento é o que vai a seguir: unha vez que recoñecemos a dimensión do "político», empezamos a decatarnos de que un dos prin- 
cipais retos aos que se enfronta a política democrática radica en domesticar a hostilidade e tentar distender o potencial antagonismo que se dá nas relacións humanas. De certo, a pregunta fundamental á que lle debe dar resposta a política democrática non é a de como acadar un consenso racional, un consenso que non exclúa a ninguén; isto faría necesario construír un "nós» que carecería do seu correspondente "eles», o cal, porén, é imposible porque, como expuxen, a condición mesma para que se poida constituír un «nós» é a delimitación dun «eles». En consecuencia, a cuestión fundamental que debe resolver a política democrática é a de como establecer esta distinción entre nós e eles, que é un elemento constitutivo da política, dun xeito compatible co recoñecemento do pluralismo. Nas sociedades modernas non se pode nin se debe erradicar o conflito, pois o que caracteriza a democracia moderna é precisamente o recoñecemento e a lexitimación deste. O que fai falta na política democrática é que se vexa aos demais non como inimigos que hai que destruír, senón como adversarios contra cuxas ideas se vai loitar, mesmo encarnizadamente, mais cuxo dereito a defender esas ideas nunca se vai pór en dúbida. Dito doutro xeito, o importante é que o conflito non adopte a forma de «antagonismo»-pelexa entre inimigos-, senón de "agonismo» - pelexa entre adversarios. Poderiamos dicir que o obxectivo da política democrática é transformar en agonismo un potencial antagonismo.

Segundo a perspectiva agonista, a categoría central da política democrática é a de «adversario», o opoñente con quen compartimos lealdade cos principios democráticos de «liberdade e igualdade para todos», malia non estarmos de acordo en como interpretar estes principios. Os adversarios loitan entre si porque queren que a súa interpretación sexa a hexemónica, mais non poñen en dúbida a lexitimidade de os seus opoñentes pelexaren co fin de acadar a vitoria da súa postura. Esta confrontación entre adversarios é o que constitúe a «loita agonista», condición básica para que exista unha democracia sa -este argumento desenvólvese en Mouffe (2000). No modelo antagonista, a tarefa fundamental da política democrática non é suprimir as paixóns nin relegalas á esfera privada co fin de establecer un consenso racional no ámbito público: é, por así dicilo, «domesticar» esas paixóns, mobilizándoas cara ao que determinan os designios democráticos, creando formas colectivas de identificación arredor dos obxectivos democráticos. 
Co fin de evitar malentendidos, querería subliñar que esta noción de «adversario» ha de distinguirse nidiamente da interpretación que se lle dá a este termo no discurso liberal. A diferenza do que acontece na postura liberal, no sentido proposto aquí non se elimina a presenza do antagonismo, senón que se «sublima». De feito, o que os liberais denominan "adversario» non é máis que un «competidor»; eles conciben o eido político como un terreo neutral onde diversos grupos compiten por asumir as posicións de poder, no que o seu obxectivo é simplemente o de desaloxar a outros para ocupar o seu lugar, sen pór en dúbida a hexemonía dominante e transformando profundamente as relacións de poder. Trátase dunha mera competencia entre elites. Polo contrario, na política agonista sempre está presente a dimensión antagonista, dado que o que está en xogo é a loita entre proxectos hexemónicos opostos que non se poden reconciliar de xeito racional, e un deles debe resultar derrotado. Velaquí unha confrontación real, mais unha confrontación que se interpreta baixo unhas condicións reguladas por un conxunto de procedementos democráticos aceptados polos adversarios.

Os teóricos liberais son incapaces de recoñecer non só a realidade primaria de que existen loitas na vida social e a imposibilidade de atoparlles solucións racionais e imparciais aos problemas políticos, senón tamén a función integradora que desempeña o conflito na democracia moderna. $\mathrm{O}$ bo funcionamento da democracia pide unha confrontación de posturas políticas democráticas; se esta falta, sempre existe o perigo de que sexa substituída por unha confrontación entre valores morais innegociables ou formas esencialistas de identificación. Facer demasiado fincapé no consenso, xunto coa aversión aos enfrontamentos, conduce á apatía e á desafección pola participación política. E por isto nunha sociedade democrática é necesario debater sobre as posibles alternativas co fin de fornecer formas políticas de identificación arredor das posturas democráticas claramente diferenciadas; ou, para empregar os termos de Niklas Luhmann, debe existir unha nidia «escisión» na cima, unha posibilidade real de escoller entre as políticas presentadas polo Goberno e as da oposición. Malia que o consenso é, sen dúbida, necesario, debe ir acompañado da disensión. É preciso que haxa consenso sobre as institucións que son constitutivas da democracia e sobre os valores ético-políticos que deben caracterizar a asociación política, mais sempre haberá desacordo verbo do significado deses valores e sobre como 
se deberían levar á práctica. Nunha democracia pluralista, eses desacordos non son só lexítimos senón tamén necesarios, pois danlle cabida a diferentes formas de identificación cidadá e constitúen a materia da que está formada a política democrática. Cando a dinámica agonista do pluralismo se ve obstaculizada pola falla de formas democráticas de identificación, non se lle pode dar unha saída democrática ás paixóns e prepárase o terreo para o xurdimento de diversas formas políticas artelladas arredor de identidades esencialistas de tipo nacionalista, relixioso ou étnico, e para que se multipliquen os enfrontamentos por valores morais innegociables.

\section{PARA ALÉN DA ESQUERDA E DA DEREITA}

En consecuencia, deberiamos recear da actual tendencia de celebrar o esvaecemento das fronteiras que separan a esquerda e a dereita, e daqueles que avogan por unha política que vaia "para alén da esquerda e da dereita». O bo funcionamento da democracia pide un intenso choque de posturas políticas democráticas; os antagonismos poden adoptar múltiples formas e é ilusorio crer que resulta posible erradicalos. Para darlle cabida á posibilidade de transformalos en relacións agonistas, é necesario canalizar politicamente a expresión do conflito dentro dun sistema democrático pluralista que ofreza oportunidades de identificación con alternativas políticas democráticas.

É neste contexto onde podemos comprobar as moi perniciosas consecuencias que ten a tese proposta por Ulrich Beck e Anthony Giddens, os cales manteñen que o modelo político de confrontación quedou obsoleto. $\mathrm{Na}$ súa opinión, o modelo político de amigo-inimigo é típico da modernidade industrial clásica, a "primeira modernidade», mais eles afirman que agora vivimos nunha diferente, a «segunda», unha modernidade "reflexiva», na cal debería facerse fincapé na «subpolítica», nas cuestións «da vida e da morte».

Igual que no caso da democracia deliberativa que critiquei ao comezo, malia que de xeito diferente, o que xace na base desta concepción da modernidade reflexiva é a posibilidade de eliminar o político na súa dimensión antagonista, así como a crenza de que se erradicaron as relacións amigo-inimigo. O que se afirma é que nas sociedades postradicionais xa non atopamos identidades colec- 
tivas construídas en función dun nós-eles, o cal significa que se evaporaron as fronteiras políticas e que, en consecuencia, a política debe «reinventarse», para empregarmos a expresión de Beck. En efecto, este autor pretende que o escepticismo xeneralizado e o papel central da dúbida que predominan hoxe en día impiden que xurdan relacións antagonistas. Entramos nunha era de ambivalencia na que ninguén pode crer, xa que se acha en posesión da verdade -crenza que era, precisamente, de onde proviñan os antagonismos- e, daquela, xa non hai motivo para que aparezan tales antagonismos. Por iso, toda tentativa de organizar as identidades colectivas arredor das nocións de esquerda e dereita e de definir o adversario quedan desacreditadas e son tachadas de «arcaicas».

$\mathrm{Na}$ súa dimensión conflitiva, a política considérase unha cousa do pasado, e o tipo de democracia que se enxalza é un modelo de consenso e totalmente despolitizado. Nos nosos días, os termos clave do discurso político son o «bo goberno» e "democracia sen partidismos». Ao meu ver, a incapacidade dos partidos tradicionais para ofreceren formas distintivas de identificación arredor das posibles alternativas é o que preparou o terreo para o actual florecemento do populismo de extrema dereita. Abofé, estes partidos populistas adoitan ser os únicos que tentan mobilizar paixóns e crear formas colectivas de identificación. Contra todos aqueles que cren que a política se pode reducir a motivacións individuais, os ultradereitistas son ben conscientes de que esta consiste sempre na creación dun «nós» que se contrapón a un «eles» e que comporta a formación de identidades colectivas. De aquí resulta o poderoso atractivo do seu discurso porque fornece formas colectivas de identificación arredor do «pobo".

Se a iso lle engadimos que, baixo o estandarte da "modernización», os partidos socialdemócratas dun gran número de países se identificaron máis ou menos exclusivamente coas clases medias e que deixaron de ocuparse das preocupacións dos sectores populares -cuxas reivindicacións se consideran «arcaicas» ou «retrógradas»-, non debería sorprender a crecente alienación de todos eses grupos que senten que as «elites do sistema» os exclúen do exercicio efectivo da cidadanía. Nun contexto en que o discurso dominante proclama que non hai alternativa á actual forma liberal da globalización e que temos que aceptar os ditados desta, pouco ten de raro que cada vez máis xente escoite con entusiasmo a aqueles que afirman que si existen alternativas e que eles lle devolverán ao pobo o poder de decisión. Unha vez que a política democrática perdeu a súa 
capacidade de conformar o debate sobre como deberiamos organizar a nosa vida en común, e unha vez que esa política se limita a garantir que se reúnan as condicións necesarias para o mercado funcionar sen incidencias, danse as circunstancias propicias para que os demagogos dotados dalgún talento articulen a frustración popular. É importante decatarse de que, en boa medida, os partidos populistas de ultradereita teñen éxito porque lle dan á xente algunha forma de esperanza, a crenza de que as cousas poderían ser distintas. Por suposto, trátase dunha esperanza ilusoria, fundamentada en premisas falsas e en mecanismos de exclusión inaceptables nos cales a xenofobia adoita desempeñar un papel fundamental; mais cando eses partidos son os únicos que propoñen un xeito de lles dar saída ás paixóns políticas, a súa pretensión de ofrecer unha alternativa resulta sedutora e probablemente aumente o seu atractivo. Para poder elaborar unha resposta axeitada é necesario entender as condicións económicas, sociais e políticas que explican o xurdimento deses partidos, e isto implica enfocar a cuestión desde un punto de vista teórico que non negue a presenza da dimensión antagonista do político.

\section{A POLÍTICA NO REXISTRO MORAL}

Coido que tamén é fundamental comprender que non é con condenas morais como se pode deter o avance do populismo de ultradereita e, por iso, a resposta que se deu maioritariamente ata agora resultou totalmente insuficiente. Abofé que as reaccións moralistas están en sintonía coa perspectiva pospolítica dominante e son de esperar, e paga a pena estudar polo miúdo esta cuestión porque nos dará algunhas ideas sobre a forma coa que se manifestan hoxe en día os antagonismos políticos.

Como vimos, o discurso dominante afirma que chegou a fin do modelo político de confrontación e nace unha sociedade de consenso que está para alén da esquerda e da dereita. Porén, eu tamén argumentei que a política sempre comporta unha distinción nós-eles, ante o cal o consenso polo que avogan os defensores da democracia sen partidismos non pode existir sen que se trace unha fronteira política e se defina un exterior, un «eles» que garanta a identidade do consenso e a coherencia do «nós». Na política estatal, actualmente, este «eles» 
desígnase de xeito moi práctico como «ultradereita», termo que se refire a unha amálgama de grupos e partidos que abranguen un amplo espectro: desde grupos marxinais de extremistas e neonazis ata a dereita autoritaria e os varios partidos populistas de extrema dereita e de nova creación. Está claro que un construto tan heteroxéneo non nos axuda a entender a natureza e as causas deste novo populismo de ultradereita, pero resulta moi útil para salvagardar a identidade dos «bos demócratas». Dado que presuntamente a política deixou de ser un eido de confrontación, é preciso un «eles» que garanta que o «nós» dos bos demócratas non se vai entender en canto adversario político. Deste xeito, a ultradereita vén moi ben porque permite trazar unha fronteira moral entre «os bos demócratas» e «a perniciosa ultradereita», que se pode condenar moralmente no canto de loitar contra ela politicamente. Por esta razón, as condenas morais e o establecemento dun "cordón sanitario» pasaron a ser a resposta dominante que se lle dá ao avance dos movementos populistas de extrema dereita.

De feito, o que está a acontecer é moi distinto do que quererían facernos crer os defensores da perspectiva pospolítica. Non se trata de que a política, cos seus antagonismos presuntamente pasados de moda, fose substituída por preocupacións morais relativas aos «problemas vitais» e aos «dereitos humanos»; moi ao contrario, a política, na súa dimensión antagonista, segue a estar moi viva, mais agora practícase no rexistro moral. Lonxe de desapareceren, as fronteiras que existen entre o nós e o eles establécense decontino pero, dado que o «eles» xa non se pode definir en sentido político, tales fronteiras trázanse en función de categorías morais, entre «nós, os bos» e «eles, os malos».

Un dos maiores defectos deste tipo de política realizada no rexistro moral consiste en que non conduce á creación dunha "esfera pública agonista», que é requisito para que exista unha vida democrática forte. Cando o opoñente non se define en sentido político, senón moral, non se pode ver como adversario senón unicamente como inimigo, e cos «malos» non é posible manter debate agonista ningún: hai que erradicalos.

$\mathrm{O}$ achegamento dos que manteñen que o modelo político de amigo-inimigo quedou invalidado acaba, de feito, reforzando o modelo de política antagonista que declararon obsoleto. Ao interpretar o «eles» como un inimigo moral, é dicir, «absoluto», fan imposible transformalo nun "adversario». No canto de axudar a crear unha esfera pública agonista sa, grazas á cal se poida manter viva a 
democracia e profundar nela, todos aqueles que proclaman a fin do antagonismo e a chegada dunha sociedade de consenso están, en realidade, a pór en perigo a democracia, creando as condicións propicias para que xurdan antagonismos que van ser imposibles de xestionar desde as institucións democráticas.

Sen unha fonda transformación do xeito de concibir a política democrática e sen un intento serio de abordar a falla de formas de identificación que poderían permitir mobilizar as paixóns democraticamente, o desafío que supoñen os partidos populistas de ultradereita vai seguir aí. En Europa estanse a trazar novas fronteiras políticas que comportan o perigo de que a antiga distinción entre esquerda e dereita logo se vexa substituída por outra, que ten moitas menos probabilidades de desembocar nun debate democrático pluralista. Polo tanto, urxe deixar atrás as miraxes do modelo político de consenso e sentar as bases dunha esfera pública agonista.

Ao se limitaren a pedir sentido común, moderación e consenso, os partidos democráticos demostran que non acaban de entender o funcionamento da lóxica política. Non comprenden que é necesario contrarrestar o populismo de ultradereita coa mobilización dos afectos e das paixóns nunha dirección democrática. $\mathrm{O}$ que non captan é que a política democrática ten que agarrarse de verdade aos desexos e fantasías da xente e, en troques de opor os intereses e os sentimentos á razón e ás paixóns, debería ofrecer formas de identificación que cuestionen efectivamente as que promove a dereita. Isto non quere dicir que a razón e os argumentos racionais teñan que desaparecer da política, senón que hai que repensar o lugar que ocupan.

\section{CARA A UNHA ORDE MUNDIAL MULTIPOLAR}

Para concluír, querería presentar algunhas reflexións referidas á situación internacional e investigar posibles escenarios en que se vai desenvolver o futuro da democracia a escala mundial. En xeral, podemos pensar en dúas posibilidades principais. Primeiramente están aqueles que piden o establecemento dunha «democracia cosmopolita» e unha "cidadanía cosmopolita» resultantes da universalización occidental do modo en que Occidente interpreta os valores democráticos e da posta en práctica da versión occidental dos dereitos humanos. 
Segundo esta perspectiva, así é como debería xurdir unha orde mundial democrática. Este achegamento ten outras variantes, mais todas comparten unha premisa: a de que o modo de vida occidental é o mellor e que, en prol do progreso moral, cómpre estendelo a todo o mundo. Velaquí o universalismo liberal que lle pretende impor as súas institucións ao resto do planeta, argüíndo que son as únicas racionais e lexítimas. Eu coido que, mesmo se as intencións dos que avogan polo modelo cosmopolita están lonxe de seren as que figuran a seguir, esta perspectiva vai xustificar necesariamente a hexemonía de Occidente e a imposición dos seus valores particulares.

Aqueles que defenden a chegada dunha «República Mundial» dotada dun corpo homoxéneo de cidadáns cosmopolitas que teñen os mesmos dereitos e obrigas, unha circunscrición electoral que coincidiría coa «humanidade», están a negar a dimensión do político que é inherente ás sociedades humanas, e pasan por alto que as relacións de poder son elementos constitutivos do social e que non se poden erradicar os conflitos nin os antagonismos. Por esta razón, se nalgún momento se establecese tal República Mundial, isto non podería significar outra cousa que a hexemonía mundial dun poder dominante que foi capaz de eliminar todas as diferenzas e de impor no planeta enteiro a súa propia visión do mundo. Este panorama tería desastrosas consecuencias e na actualidade xa somos testemuñas de que os intentos de homoxeneizar o mundo están a provocar violentas reaccións en contra por parte daquelas sociedades en que os valores e culturas de seu quedan deslexitimados pola universalización forzosa do modelo occidental.

A miña suxestión é que abandonemos eses modelos defectuosos de «cidadanía cosmopolita» e promovamos outra concepción da orde mundial, que recoñeza o pluralismo dos valores no seu sentido weberiano e nietzscheano máis pleno e con todo o que iso comporta para a política. Ao tempo que desbotamos as afirmacións dos universalistas, urxe decatarse dos perigos que implican as miraxes do discurso globalista-universalista, que concibe o progreso humano como o establecemento dunha unidade mundial baseada na aceptación do modelo occidental. Ao imaxinar que é posible unificar o mundo indo para alén do político, do conflito e da negatividade, este discurso corre o risco de provocar o choque de civilizacións que pretende evitar. Nun momento en que os Estados Unidos - coa escusa de acadar un «verdadeiro universalismo»- tentan obri- 
gar o resto do mundo a adoptar o seu sistema, a necesidade de alcanzar unha orde mundial multipolar é máis urxente ca nunca. O que está en xogo é o establecemento dunha orde pluralista na que coexistan grandes unidades rexionais e se consideren lexítimas formas plurais de democracia.

Nesta fase do proceso de globalización non quero negar que é preciso un conxunto de institucións que regulen as relacións internacionais, mais tales institucións deberían darlle cabida a un grado significativo de pluralismo e non terían que requirir a existencia dunha única estrutura de poder unificada. Por necesidade, esta estrutura debería comportar a presenza dun centro que sería o único locus da soberanía. Resulta van imaxinar un posible sistema mundial gobernado pola Razón e onde as relacións de poder quedasen neutralizadas, pois este suposto «Reino da Razón» non podería ser máis que a máscara que ocultase o imperio dun poder dominante que, identificando os seus intereses cos da humanidade, tratase todo desacordo como unha ilexítima posta en dúbida do seu liderado «racional».

Ao tentar impor a concepción occidental da democracia, considerada a única lexítima en sociedades remisas, o achegamento universalista presenta por forza aqueles que non aceptan esta perspectiva como «inimigos da civilización», co cal se negan os seus dereitos a conservaren a súa cultura e a crearen as condicións adecuadas para producirse unha confrontación antagonista entre civilizacións diferentes. Só recoñecendo a lexitimidade da existencia de diversas formas xustas de sociedade, así como o feito de que a democracia liberal non é máis ca unha forma entre outras de democracia, se poden sentar as condicións precisas para darse unha coexistencia "antagonista» de diferentes polos rexionais, dotados das súas institucións particulares. Xaora, unha orde multipolar así non eliminará o conflito, mais este terá menos probabilidades de adoptar formas antagonistas que nun mundo en que non haxa lugar para o pluralismo. 


\section{BibliografíA}

BECK, U.: The Reinvention of Politics: Rethinking Modernity in the Global Social Order, Cambridge, Polity, 1997.

DwOrkin, R.: Taking Rights Seriously, Cambridge, Mass., Harvard UP, 1977.

Giddens, A.: Beyond Left and Right, Cambridge, Polity, 1994.

Habermas, J.: «Reply to Symposium Participants», Cardozo Law Review, n. o 17, 4-5 (1996).

Luhmann, N.: «The Future of Democracy» Thesis Eleven, vol. 26 (1990).

Mouffe, C.: The Return of the Political, Londres, Verso, 1993.

Mouffe, C. (ed.): The Challenge of Carl Schmitt, Londres, Verso, 1999.

Mouffe, C.: The Democratic Paradox, Londres, Verso, 2000.

Mouffe, C.: On the Political, Londres, Routledge, 2004.

RaWLS, J.: Political Liberalism, Nova York, Columbia UP, 1993.

RORTY, R.: Objectivism, Relativism and Truth, Cambridge, Cambridge UP, 1991.

SchmitT, C.: The Concept of the Political, New Brunswick, Rutgers University Press, 1976.

STATEN, H.: Wittgenstein and Derrida, Lincoln, University of Nebraska Press, 1984. 